\title{
Effectiveness of Fungicides and Their Application Timing for the Management of Sorghum Foliar Anthracnose in the Mid-Atlantic United States
}

\author{
Bhupendra Acharya, ${ }^{1}$ Thomas N. O'Quinn, ${ }^{2}$ Wesley Everman, ${ }^{2}$ and Hillary L. Mehl ${ }^{1, \dagger}$ \\ ${ }^{1}$ Virginia Tech Tidewater Agriculture Research and Extension Center, Suffolk, VA 23437 \\ ${ }^{2}$ Department of Crop Science, North Carolina State University, Raleigh, NC 27695
}

\begin{abstract}
Sorghum anthracnose (Colletotrichum sublineola) reduces grain yield up to $50 \%$ but suggested management tactics have not yet been developed for the mid-Atlantic United States, where warm, wet conditions favor disease. Under factorial arrangement, five fungicides plus a nontreated control and four application timings were compared for foliar anthracnose control, yield, and profitability of fungicide use in grain sorghum over eight siteyears in Virginia and North Carolina. Anthracnose severity was rated at the hard dough stage, and grain yield was determined at harvest. Every percent increase in disease severity resulted in yield losses of 27 to $85 \mathrm{~kg} / \mathrm{ha}$. Pyraclostrobin and pyraclostrobin plus fluxapyroxad reduced anthracnose

compared with single applications $(P<0.01)$. However, three applications exceed the labeled maximum application for the fungicides and are not economical. Among single applications, boot or flowering timings reduced disease, and flowering applications resulted in the overall greatest yield. Results suggest that when disease onset occurs at or prior to boot, a single application of pyraclostrobin-containing fungicide at or just prior to flowering reduces anthracnose, protects yield, and increases income. However, when disease is absent or severity is low prior to flowering, fungicide application may not be profitable.
\end{abstract} $(P<0.01)$, and three applications resulted in less disease and greater yield

Keywords: chemical, economic impacts, field crops, fungi

Sorghum [Sorghum bicolor (L.)] is a cereal crop grown on nearly 43 million ha worldwide in the tropics, subtropics, and semiarid regions (U.S. Department of Agriculture Foreign Agricultural Service 2019). Sorghum is grown for food, feed, forage, fiber, sugar, fuel, and alcoholic and nonalcoholic beverages (Cuevas et al. 2014; Marley et al. 2005). In the United States, sorghum is used primarily as a feed by the poultry, beef, and pork industries and a majority of U.S. sorghum is grown in semiarid regions, including Kansas and Texas (U.S. Department of Agriculture National Agricultural Statistical Service 2018). In the mid-Atlantic region of the United States, specifically in Virginia and North Carolina, sorghum production has increased because of the demand for locally sourced animal feed that cannot be met by current corn production. Sorghum produces greater yield relative to corn in harsher climatic conditions and on marginal land (Thakur and Mathur 2000); thus, sorghum can be grown in droughtprone areas in the region that are not suitable for corn production. Sorghum production in Virginia and North Carolina increased from approximately 8,000 ha in 2005 to approximately 24,000 ha in 2016 (Balota et al. 2018).

Anthracnose [Colletotrichum sublineola P. Henn in Kabát and Bubk (formerly C. graminicola (Ces.) G. W. Wilson)] is an economically important disease of sorghum worldwide. The fungus can infect all aerial parts of the plant, including the leaves, leaf sheaths, stalks, panicles, and grains (Thakur and Mathur 2000). Foliar anthracnose is considered the most common and economically devastating stage of the disease because it interferes with photosynthate accumulation by covering the leaf surface, thereby reducing yield. Environmental conditions during the growing season in the mid-Atlantic are typically favorable for anthracnose

${ }^{\dagger}$ Corresponding author: H. L. Mehl; hlmehl@vt.edu

Funding: This research was supported by Smithfield Murphy Brown, LLC.

The author(s) declare no conflict of interest.

Accepted for publication 25 May 2019.

(C) 2019 The American Phytopathological Society development. Disease outbreaks occur during periods of high rainfall or humidity $>90 \%$ and when the temperature ranges from 25 to $30^{\circ} \mathrm{C}$ (Pande et al. 1994). Typical foliar symptoms appear as small, circular, elliptical, or elongated spots that have gray to straw-colored centers with visible setae from acervuli that can coalesce and cover the entire leaf at advanced stages (Thakur and Mathur 2000). Anthracnose is a polycyclic disease and infection is enhanced by rain and contact of leaves with infested soil (Ngugi et al. 2000; Thakur and Mathur 2000). In severe cases, defoliation and premature senescence occurs (Thakur and Mathur 2000). Under favorable conditions, development of anthracnose is more rapid from flowering through the grain filling stage compared with early developmental stages of sorghum ( $\mathrm{Li}$ and TeBeest 2009; Ngugi et al. 2000; Pande et al. 1994). The pathogen can overwinter in crop debris as microsclerotia and mycelia, in infected seed, and on weed hosts such as johnsongrass [S. halepense (L.) Pers.] (Cardwell et al. 1989; Gwary et al. 2006; Tesso et al. 2012; Thakur and Mathur 2000).

A few prior studies have demonstrated sorghum yield losses to anthracnose and the potential for fungicides to reduce disease and protect grain yield. Anthracnose severity as low as $20 \%$ can impact yield (Ngugi et al. 2000) and yield losses as high as 50\% have been reported in susceptible sorghum cultivars (Thakur and Mathur 2000). In sorghum producing regions in Nigeria and Brazil, use of fungicides (seed and foliar) has proven successful in managing this disease (Gwary et al. 2008; Marley 2004; Pinto 2003). Gwary et al. (2008) reported that seed treated with fungicides, metalaxyl plus carboxin (Apron Plus 50DS) and thiram plus thiophanate methyl (Super Homai 70\% WP), presented reductions in leaf anthracnose severity up to 70 days after planting compared with nontreated controls, but yield differences were not observed. Similarly, three foliar applications of benomyl at 7-day intervals beginning at disease onset resulted in lower anthracnose severity and increased yield compared with the nontreated control (Marley 2004). Pinto (2003) also reported that three applications of the fungicides procloraz, carbendazim, benomyl, and azoxystrobin at 10-day intervals were effective in controlling anthracnose and increasing yield. However, multiple foliar fungicide applications are unlikely to be economical for sorghum growers, and a single optimum application timing was not determined in these studies (Marley et al. 2005). 
Diseases in semiarid regions are managed through breeding for genetic resistance and seed treatment fungicides, but foliar fungicides are not typically recommended because of the inconsistent occurrence and low severity of foliar diseases (Fromme et al. 2017; Thakur and Mathur 2000). However, with the subtropical conditions in the mid-Atlantic United States, anthracnose severity is greater than that in semiarid regions of the United States. A majority of the sorghum hybrids grown in the United States have been bred to be adapted to semiarid environments; thus, high-yield-producing hybrids may be susceptible to fungal diseases including anthracnose when grown in humid, wet environments. The effectiveness of foliar fungicides and optimum application timings have not yet been evaluated for sorghum anthracnose management in the mid-Atlantic region. Therefore, the objectives of this study were to (i) compare five fungicides and four application timings for anthracnose control and yield protection, (ii) estimate yield losses associated with sorghum anthracnose in the mid-Atlantic region, and (iii) evaluate the profitability of foliar fungicide applications for sorghum production in the region.

\section{Materials and Methods}

Field trials. Field experiments were conducted over eight siteyears in Virginia and North Carolina from 2015 to 2017. Anthracnose-susceptible sorghum hybrid 84P80 (DuPont Pioneer, Johnston, IA) was planted at a rate of approximately 193,000 seeds/ha. Information on previous crop, planting date, fungicide applications, date of anthracnose onset, and harvest date is provided in Table 1. Soil fertility, insects, and weeds were managed following standard practices for sorghum in the region (Flessner and Taylor 2019). In 2016 and 2017, sugarcane aphids were controlled by using sulfoxaflor (as 0.1 liters of Transform/ha; Dow AgroSciences, Indianapolis, IN) or flupyradifurone (as 0.4 liters of Sivanto/ha; Bayer CropScience, Research Triangle, NC) and alternating the chemistry when multiple sprays were required.

Environmental data collection. Weather data for all North Carolina experimental sites were obtained from the North Carolina Climate Retrieval and Observations Network of the Southeast database (https://climate.ncsu.edu/cronos). The environmental data for Rocky Mount and Lewiston-Woodville locations were recorded at on-site weather stations. Data for the Kinston location were obtained from a weather station at Cunningham Research Station located $7.1 \mathrm{~km}$ northeast from the experimental site. Weather data for the Suffolk site were obtained from PeanutCotton InfoNet (https://webipm.ento.vt.edu/cgi-bin/infonet1.cgi), which reports data collected at the research farm where experiments were conducted.
Fungicides and application timings. The experiment included a $6 \times 4$ factorial arrangement of treatments in a randomized complete block design. The main factors were fungicide (nontreated control or one of five different fungicides) and application timing. Fungicides and rates were as follows: azoxystrobin (as 0.44 liters of Quadris 2.08 SC/ha; Syngenta Crop Protection, Greensboro, NC), pyraclostrobin (as 0.44 liters of Headline SC/ha; BASF Corporation, Research Triangle Park, NC), picoxystrobin (as 0.44 liters of Aproach SC/ha; DuPont Crop Protection, Wilmington, DE), pyraclostrobin plus fluxapyroxad (as 0.29 liters of Priaxor 4.17 SC/ha; BASF Corporation), and propiconazole (as 0.29 liters of Tilt 3.6 EC/ha; Syngenta Crop Protection). The four application timings were boot (head enclosed in a swollen leaf sheath), flower (beginning of flowering in $50 \%$ of the plants), late (14 days after flower application), or applications at all three stages (Vanderlip and Reeves 1972). Each site had three or

Table 2. Monthly rainfall and average temperatures during the sorghum growing season for eight site-years in Virginia and North Carolina

\begin{tabular}{lrrrrrr} 
Site $^{\mathbf{z}}$ & May & June & July & August & September & October \\
\hline Rainfall (mm) & & & & & & \\
SF-15 & 12 & 161 & 96 & 55 & 115 & 74 \\
RM-15 & 60 & 84 & 54 & 82 & 167 & 137 \\
RM-16 & 94 & 111 & 491 & 85 & 246 & 259 \\
KS-16 & 175 & 112 & 132 & 128 & 240 & 84 \\
SF-17 & 120 & 89 & 60 & 186 & 94 & 88 \\
RM-17 & 125 & 122 & 151 & 176 & 76 & 87 \\
LW-17 & 148 & 143 & 189 & 128 & 82 & 69 \\
KS-17 & 93 & 120 & 43 & 86 & 108 & 77 \\
Mean temperature $\left({ }^{\circ}\right.$ C) & & & & & & \\
SF-15 & 21 & 26 & 26 & 25 & 23 & 16 \\
RM-15 & 21 & 26 & 26 & 25 & 23 & 16 \\
RM-16 & 20 & 24 & 27 & 27 & 23 & 18 \\
KS-16 & 20 & 25 & 27 & 27 & 24 & 19 \\
SF-17 & 20 & 26 & 28 & 25 & 22 & 21 \\
RM-17 & 21 & 24 & 26 & 25 & 22 & 18 \\
LW-17 & 20 & 24 & 26 & 24 & 22 & 18 \\
KS-17 & 22 & 25 & 27 & 25 & 22 & 18 \\
\hline
\end{tabular}

${ }^{\mathrm{z}}$ Experiment locations were as follows: $\mathrm{SF}=$ Suffolk, Virginia (Tidewater Agricultural Research and Extension Center); RM = Rocky Mount, North Carolina (Upper Coastal Plain Research Station); KS = Kinston, North Carolina (Casewell Development Center Research Farm); and LW = LewistonWoodville, North Carolina (Peanut Belt Research Station). Numbers 15, 16, and 17 following the location abbreviation indicate the years 2015, 2016, and 2017, respectively.

Table 1. Location, previous crop, and dates of planting, fungicide applications, anthracnose disease onset, and harvest for each experiment

\begin{tabular}{|c|c|c|c|c|c|c|c|c|c|c|}
\hline \multirow[b]{2}{*}{ Site $^{\mathrm{v}}$} & \multirow[b]{2}{*}{ Previous crop } & \multirow[b]{2}{*}{ Planting date } & \multicolumn{3}{|c|}{ Fungicide (DAP)w $^{\mathbf{w}}$} & \multirow{2}{*}{$\begin{array}{c}\text { Disease } \\
\text { onset (DAP) }\end{array}$} & \multirow{2}{*}{$\begin{array}{l}\text { AUDPC, plant } \\
\text { to flower }\end{array}$} & \multirow{2}{*}{$\begin{array}{c}\text { Disease } \\
\text { severity }(\%)^{y}\end{array}$} & \multirow{2}{*}{$\begin{array}{c}\text { Yield } \\
\text { loss }(\%)^{\mathrm{z}}\end{array}$} & \multirow[b]{2}{*}{ Harvest date } \\
\hline & & & Boot & Flower & Late & & & & & \\
\hline SF-15 & Soybean & 6 June & 53 & 61 & 75 & 51 & 67 & 78 & -1 & 20 October \\
\hline RM-15 & Soybean & 28 May & 60 & 67 & 81 & 64 & 1 & 56 & 11 & 21 October \\
\hline RM-16 & Soybean & 27 May & 49 & 61 & 74 & 43 & 172 & 44 & 55 & 3 October \\
\hline KS-16 & Soybean & 14 June & 44 & 59 & 73 & 72 & 0 & 24 & 1 & 4 October \\
\hline SF-17 & Cotton & 26 June & 51 & 58 & 71 & 48 & 7 & 40 & 53 & 2 November \\
\hline RM-17 & Soybean & 12 June & 53 & 64 & 79 & 66 & 3 & 32 & 12 & 19 October \\
\hline LW-17 & Sorghum & 8 June & 62 & 68 & 84 & 50 & 28 & 40 & 29 & 4 October \\
\hline KS-17 & Soybean & 7 June & 62 & 70 & 90 & 71 & 2 & 7 & 14 & 23 October \\
\hline
\end{tabular}

v Experiment locations were as follows: SF = Suffolk, Virginia (Tidewater Agricultural Research and Extension Center); RM = Rocky Mount, North Carolina (Upper Coastal Plain Research Station); KS = Kinston, North Carolina (Casewell Development Center Research Farm); and LW = Lewiston-Woodville, North Carolina (Peanut Belt Research Station). Numbers 15, 16, and 17 following the location abbreviation indicate the years 2015, 2016, and 2017, respectively.

${ }^{\mathrm{w}} \mathrm{DAP}=$ days after planting.

$x$ AUDPC $=$ area under the disease progress curve. AUDPC was calculated using the anthracnose disease severity ratings from planting until flowering.

y Anthracnose severity was evaluated at the hard dough stage of the sorghum crop. Disease severity was rated as an estimate of the total percent leaf area with signs and symptoms of anthracnose.

${ }^{\mathrm{z}}$ Maximum percent yield loss was calculated for each experiment based on the percent difference in yield for the nontreated control versus the highest yielding fungicide treatment. 
four replications with 2.4-m fallow alleys between blocks. Each treatment plot consisted of four rows that were $9 \mathrm{~m}$ long by $3.7 \mathrm{~m}$ wide except for the 2016 and 2017 experiments in Kinston, North Carolina (KS-16 and KS-17, respectively), which had three rows with dimensions of $9 \mathrm{~m}$ by $2.8 \mathrm{~m}$. Anthracnose severity was evaluated biweekly as a visual estimate of the percentage of leaf area with symptoms and signs of sorghum anthracnose starting at the boot stage.

At the sites in Virginia, fungicide treatments were applied with a Lee Spider Sprayer having eight 8002 VS nozzles spaced $46 \mathrm{~cm}$ apart delivering 186 liters/ha at $262 \mathrm{kPa}$. At the sites in North Carolina, fungicide treatments were applied with a backpack sprayer having eight XR 11002 flat fan nozzles spaced $46 \mathrm{~cm}$ apart delivering 140.3 liters/ha at $207 \mathrm{kPa}$. At the end of the season, grain was harvested from the center two rows of each plot for all of the sites except for Kinston, where all three rows of a plot were harvested, using a mechanical harvester equipped with a grain gauge and moisture meter. Yield, moisture, and test weight were measured from each plot at harvest, and yield/hectare was calculated based on a standard moisture content adjusted to $14 \%$.

Profitability calculations. The profitability of fungicide applications in sorghum was estimated in U.S. dollars (USD) based on average local prices from three retailers each in Virginia and North Carolina for Priaxor (\$120.2/liter), Headline (\$108.6/liter), Quadris (\$48.2/liter), Aproach (\$67.0/liwter), and Tilt (\$22.1/liter). The estimated machinery and labor costs for fungicide applications were $\$ 49.3 /$ ha and $\$ 33.8 /$ ha, respectively, and the projected price of grain sorghum in Virginia and North Carolina for the year 2018 was $\$ 0.17 / \mathrm{kg}$ (https://cals.ncsu.edu/are-extension/grain-budgets/). The increase in yield required to cover the cost of use of a fungicide (break-even yield) was determined using the following formula, modified from (Weisz et al. 2011):

Yield (in $\mathrm{kg} / \mathrm{ha}$ ) required to cover the cost of using a fungicide

$=[$ Fungicide cost (in USD)

+ Machinery and labor cost for fungicide spray

(in USD) per hectare]/[Grain sorghum price (in USD/kg)]

Farm profitability of including a fungicide application in grain sorghum production in the mid-Atlantic was calculated by comparing the monetary return with the nontreated control per hectare using the following formula (Lopez et al. 2015):

Net return(in USD)

$=$ Grain Sorghum price $($ in USD $/ \mathrm{kg}$ )

$\times$ Y Yield(in $\mathrm{kg} / \mathrm{ha}$ ) obtained from a fungicide application

- Yield (in $\mathrm{kg} / \mathrm{ha}$ ) obtained from the nontreated control]

- [Fungicide cost(in USD/ha)

+ Machinery and labor cost for fungicide spray (in USD/ha)]

Statistical analyses. In some experiments, disease onset was late in the season so disease severity could not be evaluated until the hard dough stage, when grains changed color from green to brown and were hard when squeezed. Hence, only the final disease severity evaluation at the hard dough stage was used for statistical analysis and comparison. An initial analysis was performed using block, fungicide, application timing, site-year, and interactions among these factors for anthracnose severity in the model. The effect of siteyear and its interactions with fungicide and application timing were significant, so each experiment was analyzed separately. Percentage anthracnose severity data were arcsine square root transformed prior to analysis to meet the assumptions of analysis of variance (ANOVA). Data for anthracnose severity and yield were analyzed using the general linear model procedure $(\mathrm{glm})$ in R software version 3.2.2 using the package, agricolae (de Mendiburu 2015). In addition, regression analyses of environmental variables and disease and anthracnose severity and yield were conducted using the linear model procedure $(\mathrm{lm})$ in agricolae. Anthracnose severity was subjected to ANOVA using a model that included block, fungicide, application timing, and their interactions as sources of variation. Means were compared using the Tukey honest significant difference test at the significance level of $\alpha=0.05$, and back-transformed values are presented.

\section{Results}

Date of foliar anthracnose onset and rate of disease development in the nontreated controls varied among experiments. Site-years where disease onset was prior to the boot stage had the most rapid rate of disease development between planting and flowering (Table 1).

Table 3. Impact of fungicides and application timings on foliar anthracnose severity in sorghum hybrid P84P80 at eight site-years in Virginia and North Carolina

\begin{tabular}{|c|c|c|c|c|c|c|c|c|}
\hline \multirow[b]{2}{*}{ Variable $^{y}$} & \multicolumn{8}{|c|}{ Anthracnose severity $(\%)^{\mathrm{z}}$} \\
\hline & $\overline{\text { SF-15 }}$ & RM-15 & RM-16 & KS-16 & SF-17 & RM-17 & LW-17 & KS-17 \\
\hline \multicolumn{9}{|l|}{ Fungicide (F) } \\
\hline NTC & $71.9 \mathrm{a}$ & $63.1 \mathrm{a}$ & $44.7 \mathrm{a}$ & $16.7 \mathrm{a}$ & $43.4 \mathrm{a}$ & $27.4 \mathrm{a}$ & $82.5 \mathrm{a}$ & $4.7 \mathrm{a}$ \\
\hline PROP & $71.2 \mathrm{a}$ & $61.8 \mathrm{a}$ & $42.8 \mathrm{ab}$ & $12.9 \mathrm{a}$ & $42.2 \mathrm{a}$ & $24.2 \mathrm{ab}$ & $79.4 \mathrm{ab}$ & $8.4 \mathrm{a}$ \\
\hline AZOX & $72.6 \mathrm{a}$ & $62.4 \mathrm{a}$ & $38.7 \mathrm{~b}$ & $9.9 \mathrm{ab}$ & $27.3 \mathrm{~b}$ & $14.7 \mathrm{~b}$ & $64.4 \mathrm{~b}$ & $3.5 \mathrm{ab}$ \\
\hline PICO & $72.6 \mathrm{a}$ & $65.9 \mathrm{a}$ & $42.1 \mathrm{ab}$ & $10.5 \mathrm{a}$ & $37.0 \mathrm{ab}$ & $18.3 \mathrm{ab}$ & $77.8 \mathrm{ab}$ & $3.7 \mathrm{ab}$ \\
\hline PYRA & $70.6 \mathrm{a}$ & $62.4 \mathrm{a}$ & $25.9 \mathrm{c}$ & $1.5 \mathrm{c}$ & $2.3 \mathrm{~d}$ & $2.3 \mathrm{c}$ & $23.7 \mathrm{c}$ & $0.5 \mathrm{~b}$ \\
\hline PYRA + FLUX & $63.8 \mathrm{~b}$ & $52.8 \mathrm{~b}$ & $22.4 \mathrm{c}$ & $2.5 \mathrm{bc}$ & $8.6 \mathrm{c}$ & $2.8 \mathrm{c}$ & $28.3 \mathrm{c}$ & $0.5 \mathrm{~b}$ \\
\hline$P$ value & $<0.01$ & $<0.01$ & $<0.01$ & $<0.01$ & $<0.01$ & $<0.01$ & $<0.01$ & $<0.01$ \\
\hline \multicolumn{9}{|l|}{ Application (A) } \\
\hline Boot & 70.0 & 63.1 & $39.0 \mathrm{ab}$ & 10.1 & $25.6 \mathrm{ab}$ & $16.7 \mathrm{a}$ & $56.0 \mathrm{~b}$ & 3.6 \\
\hline Flower & 71.7 & 59.9 & $36.5 \mathrm{~b}$ & 9.4 & $24.2 \mathrm{ab}$ & $14.5 \mathrm{ab}$ & $61.6 \mathrm{~b}$ & 2.7 \\
\hline Late & 71.7 & 60.8 & $40.6 \mathrm{a}$ & 8.6 & $29.7 \mathrm{a}$ & $13.3 \mathrm{ab}$ & $78.7 \mathrm{a}$ & 4.2 \\
\hline All & 68.6 & 61.8 & $27.5 \mathrm{c}$ & 4.5 & $17.5 \mathrm{~b}$ & $8.5 \mathrm{~b}$ & $42.2 \mathrm{c}$ & 1.6 \\
\hline$P$ value & 0.21 & 0.52 & $<0.01$ & 0.09 & $<0.01$ & 0.02 & $<0.01$ & 0.18 \\
\hline \multicolumn{9}{|l|}{$\mathrm{F} \times \mathrm{A}$} \\
\hline$P$ value & 0.42 & 0.35 & $<0.01$ & 0.24 & 0.6 & 0.08 & $<0.01$ & 0.57 \\
\hline
\end{tabular}

y Tested variables included fungicides $(\mathrm{F})$ and application timings (A). Significant treatment effects and treatment interactions $(\mathrm{F} \times \mathrm{A})$ were determined using a factorial analysis of variance. NTC = nontreated control; PROP = propiconazole (as Tilt); AZOX = azoxystrobin (as Quadris); PICO = picoxystrobin (as Aproach); PYRA = pyraclostrobin (as Headline); and PYRA + FLUX = pyraclostrobin + fluxapyroxad (as Priaxor).

${ }^{\mathrm{z}}$ Anthracnose severity was rated as a visual estimate of the percent leaf area with signs and symptoms of sorghum anthracnose. Experiment locations were as follows: SF = Suffolk, Virginia (Tidewater Agricultural Research and Extension Center); RM = Rocky Mount, North Carolina (Upper Coastal Plain Research Station); KS = Kinston, North Carolina (Casewell Development Center Research Farm); and LW = Lewiston-Woodville, North Carolina (Peanut Belt Research Station). Numbers 15, 16, and 17 following the location abbreviation indicate the years 2015, 2016, and 2017, respectively. Within a treatment factor, means followed by the same letter are not significantly different from each other according to the Tukey honest significant difference test. 
However, there was a poor relationship between anthracnose severity at the hard dough stage and either disease onset $(P=0.15, r=-0.56)$ or disease development prior to flowering $(P=0.40, r=0.35)$. Percent yield losses attributable to disease at each site-year were estimated based on the difference between the nontreated control and the greatest yield-producing fungicide treatment. Among the disease variables, disease onset relative to planting was most predictive of yield losses $(P=0.047, r=-0.71)$ with earlier disease onset resulting in greater yield losses.

Relationships between environmental variables, disease, and yield losses were examined for the eight experiments. Mean monthly temperatures were similar among site-years; however,

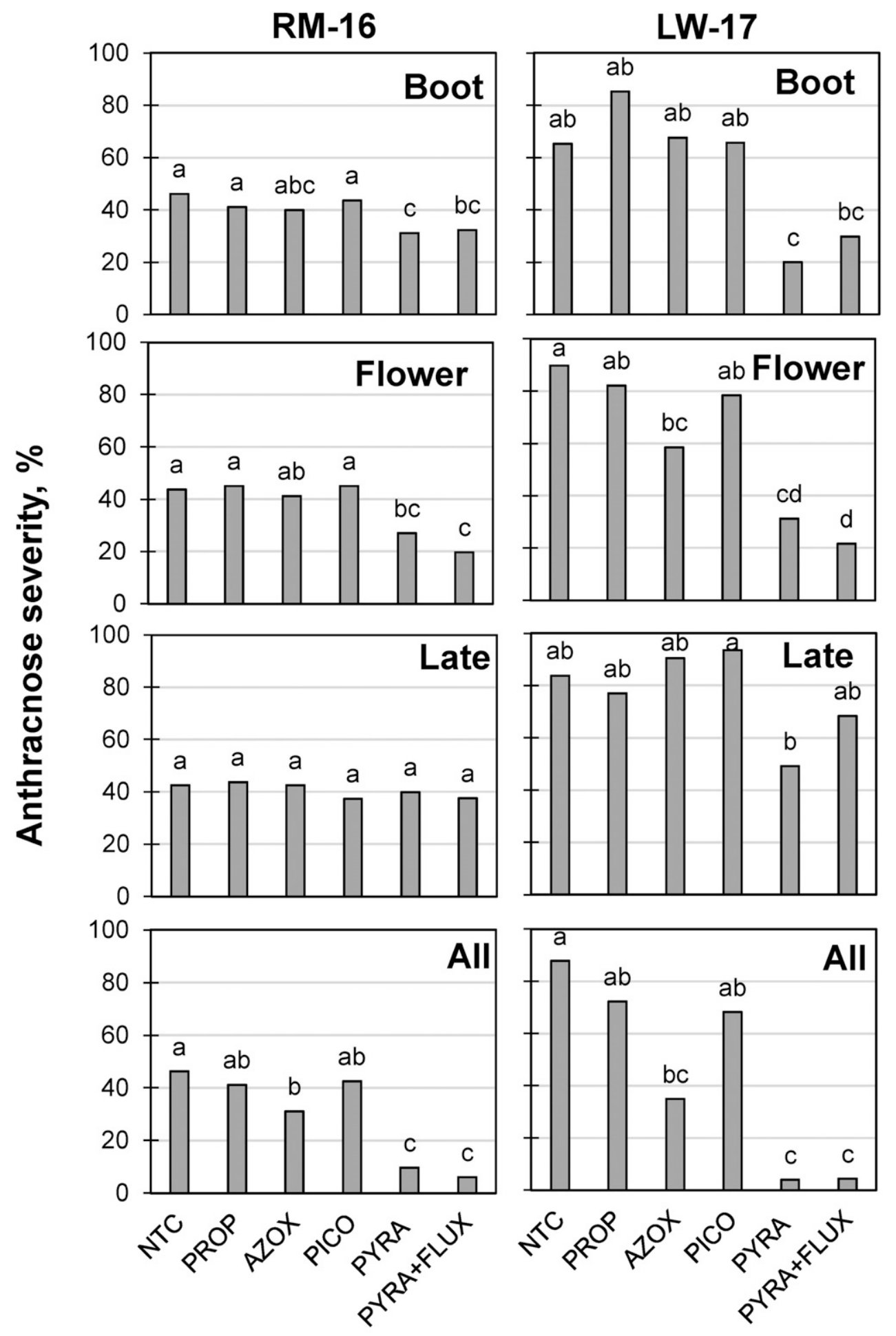

Fungicide

Fig. 1. Variation in the severity of leaf anthracnose in sorghum hybrid P84P80 owing to interaction of fungicides and application timings at Rocky Mount, North Carolina, in 2016 (RM-16) and Lewiston, North Carolina, in 2017 (LW-17). Fungicides were applied at the boot stage, flowering stage, 14 days after the flowering stage (late), or at all three timings (all). NTC = nontreated control, PROP = propiconazole (as Tilt), AZOX = azoxystrobin (as Quadris), PICO = picoxystrobin (as Aproach), PYRA = pyraclostrobin (as Headline), and PYRA+FLUX = pyraclostrobin plus fluxapyroxad (as Priaxor). Bars with the same letter are not significantly different from each other according to the Tukey honest significant difference test. 
total precipitation differed, with some sites receiving more precipitation than others during the growing season (Table 2). There was no relationship between anthracnose severity at the hard dough stage and monthly rainfall, but greater rainfall the month prior to flowering was associated with earlier disease onset $(P=$ $0.068, r=-0.67)$, more rapid rates of disease development prior to flowering $(P=0.007, r=0.85)$, and greater percent yield losses $(P=0.034, r=0.74)$. Notably, even though the Rocky Mount site in 2016 (RM-16) only had moderate anthracnose severity at the hard dough stage, it had 2.5 to 11 times greater rainfall compared with other site-years the month prior to flowering, as well as the earliest disease onset, the greatest rate of disease development prior to flowering, and the greatest percent yield losses among the eight experiments (Tables 1 and 2).

Anthracnose severity varied among fungicide treatments at all site-years, but the impact of application timing and the interaction between fungicide and timing varied among experiments (Table 3). Overall, pyraclostrobin and pyraclostrobin plus fluxapyroxad provided the greatest reduction in anthracnose severity, followed by azoxystrobin; picoxystrobin and propiconazole treatments were not significantly different from the nontreated control regardless of site-year. When application timing had an impact on disease severity, three fungicide applications provided the greatest level of disease control, and fungicides applied 2 weeks after flowering resulted in the least control. In two experiments, there was a significant fungicide $\times$ application timing interaction (Fig. 1; Table 3). Pyraclostrobin and pyraclostrobin plus fluxapyroxad reduced disease severity when applied at the boot, flower, or all three timings, but fungicides did not reduce anthracnose severity when applied 2 weeks after flowering.

Effects of fungicides and application timings on yield varied by experiment (Table 4). Differences in yield between the nontreated control and fungicide treatments were detected at only three of the eight site-years, and only the pyraclostrobin and pyraclostrobin plus fluxapyroxad treatments resulted in greater yield. Three applications resulted in numerically greater yield compared with single applications, but overall, boot and flower applications had greater yield compared with late fungicide applications (Table 4). For RM-16, the experiment with the earliest disease onset and greatest yield losses, there was a significant fungicide $\times$ application timing interaction and pyraclostrobin and pyraclostrobin plus fluxapyroxad protected yield when applied at flowering or all three timings but did not protect yield when applied at boot or 2 weeks after flowering (Fig. 2). For three experiments, there was not a relationship between leaf anthracnose severity and yield (Table 5). For the Kinston experiments in 2016 and 2017, there was a significant but poor correlation between disease severity and grain yield. There was a negative linear correlation of leaf anthracnose severity and yield for three experiments, with correlation coefficient $(r)$ values ranging from -0.75 to -0.86 and yield losses ranging from 27 to $85 \mathrm{~kg} / \mathrm{ha}$ attributable to each percentage of leaf area with anthracnose (Table 5).

Two fungicides, pyraclostrobin and pyraclostrobin plus fluxapyroxad, protected yield compared with the nontreated control and other fungicides tested in this study (Fig. 2; Table 4). Hence, the profitability calculations were performed for a single application of these two fungicides. Because the late application of fungicides did not reduce anthracnose severity or protect yield compared with the nontreated control, the profitability calculations were conducted for boot and flower applications only. A single application of pyraclostrobin resulted in yield 49 to $2,448 \mathrm{~kg} /$ ha greater than the nontreated control, and a single application of pyraclostrobin plus fluxapyroxad resulted in yields 111 to $2,694 \mathrm{~kg} / \mathrm{ha}$ greater than the nontreated control (Table 4). To cover the cost of a single fungicide application, a yield increase of 769 and $693 \mathrm{~kg} / \mathrm{ha}$ was needed for pyraclostrobin (\$130.70/ha) and pyraclostrobin plus fluxapyroxad (\$117.80/ha), respectively. Even though the only significant yield difference between fungicide applied at the boot stage and the nontreated control was for pyraclostrobin plus fluxapyroxad at a single site-year, the value of the difference in yield between a single application at boot compared with the nontreated control exceeded the cost of fungicide and resulted in a positive return on investment ranging from $\$ 13$ to $\$ 307 /$ ha in four of the experiments (Fig. 3, top). When these fungicides were applied at the flowering stage, both fungicides had greater yield compared with the nontreated control at two site-years, but there was a positive net return ranging from $\$ 10$ to $\$ 373 /$ ha from a single fungicide application for six of the eight experiments (Fig. 3 , bottom).

\section{Discussion}

In this study, it was documented that foliar anthracnose has the potential to limit sorghum grain yield in wet, humid regions such as the

Table 4. Impact of fungicides and application timings on grain yield in sorghum hybrid P84P80 at eight site-years in Virginia and North Carolina

\begin{tabular}{|c|c|c|c|c|c|c|c|c|}
\hline \multirow[b]{2}{*}{ Treatment $^{y}$} & \multicolumn{8}{|c|}{ Yield $(\mathrm{kg} / \mathrm{ha})^{\mathrm{z}}$} \\
\hline & SF-15 & RM-15 & RM-16 & KS-16 & SF-17 & RM-17 & LW-17 & KS-17 \\
\hline \multicolumn{9}{|l|}{ Fungicide $(\mathrm{F})$} \\
\hline NTC & 4,910 & 3,880 & $1,250 \mathrm{~b}$ & 5,195 & $2,398 \mathrm{~b}$ & 5,427 & $2,970 \mathrm{~b}$ & 3,666 \\
\hline PROP & 4,840 & 3,573 & $1,408 \mathrm{~b}$ & 5,211 & $2,697 \mathrm{~b}$ & 5,850 & $2,523 \mathrm{~b}$ & 3,515 \\
\hline AZOX & 4,810 & 3,061 & $1,799 \mathrm{~b}$ & 5,534 & $3,195 \mathrm{~b}$ & 5,861 & $2,713 \mathrm{~b}$ & 4,161 \\
\hline $\mathrm{PICO}$ & 4,625 & 3,274 & $1,506 \mathrm{~b}$ & 5,180 & $2,892 \mathrm{~b}$ & 5,594 & $2,809 \mathrm{~b}$ & 4,075 \\
\hline PYRA & 4,751 & 4,342 & $2,771 \mathrm{a}$ & 5,244 & 4,846 a & 6,134 & 3,977 a & 4,020 \\
\hline PYRA + FLUX & 4,787 & 3,991 & $2,804 \mathrm{a}$ & 4,980 & $5,092 \mathrm{a}$ & 6,053 & $4,191 \mathrm{a}$ & 4,266 \\
\hline$P$ value & 0.66 & 0.05 & $<0.01$ & 0.55 & $<0.01$ & 0.16 & $<0.01$ & 0.11 \\
\hline \multicolumn{9}{|l|}{ Application (A) } \\
\hline Boot & 4,874 & 3,561 & $1,770 \mathrm{~b}$ & 5,325 & $3,548 \mathrm{ab}$ & 5,810 & $3,318 \mathrm{a}$ & 3,954 \\
\hline Flower & 4,783 & 3,580 & $1,796 \mathrm{~b}$ & 5,405 & $3,472 \mathrm{~b}$ & 5,893 & $3,366 \mathrm{a}$ & 3,819 \\
\hline Late & 4,700 & 3,961 & $1,524 \mathrm{~b}$ & 5,065 & $2,929 \mathrm{~b}$ & 5,598 & $2,535 \mathrm{~b}$ & 3,928 \\
\hline All & 4,793 & 3,602 & $2,602 \mathrm{a}$ & 5,101 & $4,132 \mathrm{a}$ & 5,978 & $3,569 \mathrm{a}$ & 4,102 \\
\hline$P$ value & 0.66 & 0.60 & $<0.01$ & 0.371 & $<0.01$ & 0.445 & $<0.01$ & 0.719 \\
\hline \multicolumn{9}{|l|}{$\mathrm{F} \times \mathrm{A}$} \\
\hline$P$ value & 0.91 & 0.95 & $<0.01$ & 0.74 & 0.24 & 0.45 & 0.19 & 0.35 \\
\hline
\end{tabular}

y Tested variables included fungicides $(\mathrm{F})$ and application timings $(\mathrm{A})$. Significant treatment effects and treatment $(\mathrm{F} \times \mathrm{A})$ interactions were determined using a factorial analysis of variance. NTC = nontreated control; PROP = propiconazole (as Tilt); AZOX = azoxystrobin (as Quadris); PICO = picoxystrobin (as Aproach); PYRA = pyraclostrobin (as Headline); and PYRA + FLUX = pyraclostrobin plus fluxapyroxad (as Priaxor).

${ }^{\mathrm{z}}$ Experiment locations were as follows: SF = Suffolk, Virginia (Tidewater Agricultural Research and Extension Center); RM = Rocky Mount, North Carolina (Upper Coastal Plain Research Station); KS = Kinston, North Carolina (Casewell Development Center Research Farm); and LW = Lewiston-Woodville, North Carolina (Peanut Belt Research Station). Numbers 15, 16, and 17 following the location abbreviation indicate the years 2015, 2016, and 2017, respectively. Within a treatment factor, means followed by the same letter are not significantly different from each other according to the Tukey honest significant difference test. 
mid-Atlantic United States. We evaluated five fungicides and four application timings for the efficacy in managing foliar anthracnose and protecting grain yield in sorghum. Three applications of either pyraclostrobin or pyraclostrobin plus fluxapyroxad were effective
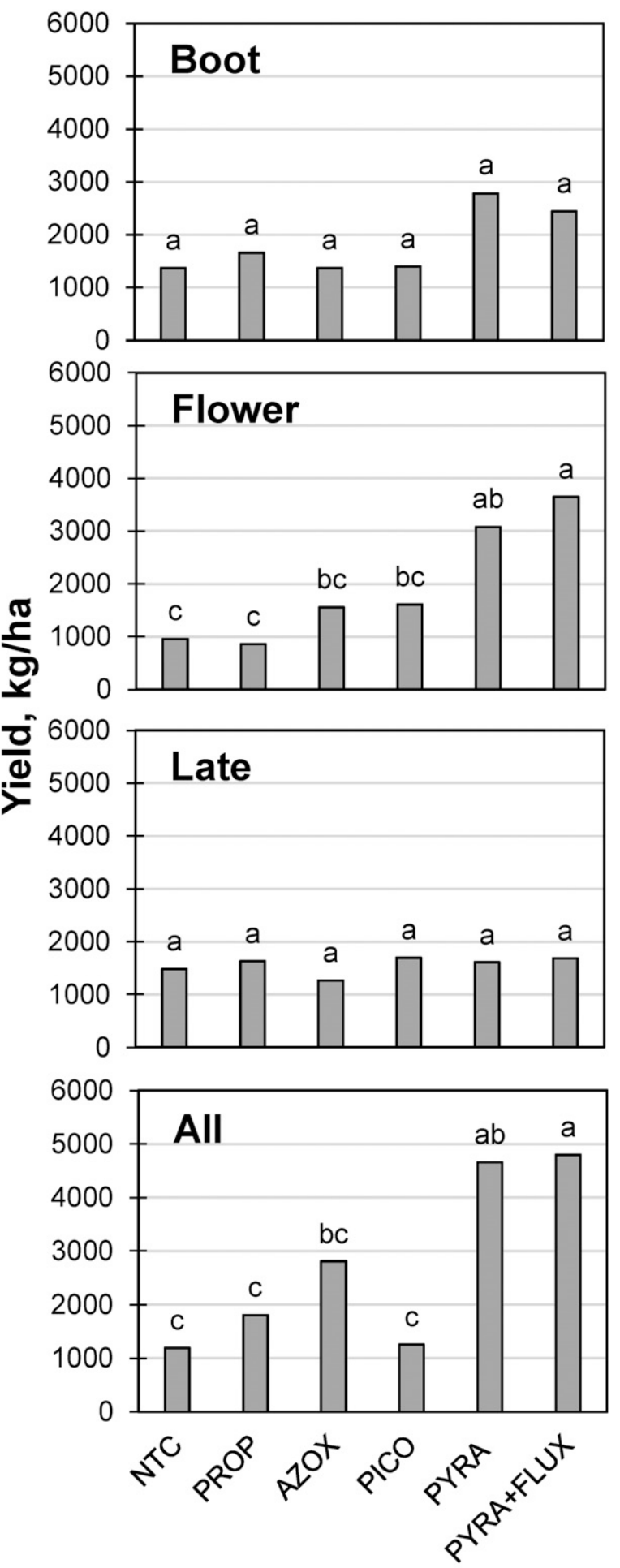

Fungicide

Fig. 2. Variation in grain yield of sorghum hybrid P84P80 owing to interaction of fungicides and application timings at Rocky Mount, North Carolina, in 2016. Fungicides were applied at the boot stage, flowering stage, 14 days after the flowering stage (late), or at all three timings (all). NTC $=$ nontreated control, PROP = propiconazole (as Tilt), AZOX = azoxystrobin (as Quadris), PICO = picoxystrobin (as Aproach), PYRA = pyraclostrobin (as Headline), and PYRA+FLUX = pyraclostrobin plus fluxapyroxad (as Priaxor). Bars with the same letter are not significantly different from each other according to the Tukey honest significant difference test. in reducing anthracnose severity and protecting yield. However, these products are not labeled for more than one application in a growing season, and more than one fungicide application is unlikely to be economical for growers. The labeled application timing for both fungicides is no later than early flowering; among the single applications, boot or flowering timings provided the greatest disease control. However, yield protection was most consistent when fungicides were applied at flowering, which indicates that this is, in most cases, the optimum fungicide application timing for sorghum anthracnose.

Time of disease onset and environmental conditions varied among experiments, and this likely impacted the levels of anthracnose control and yield response to fungicides observed in this study. Among the eight experiments, RM-16 received the greatest amount of rainfall prior to flowering, had the earliest disease onset relative to planting of the sorghum crop, and had the greatest anthracnose severity between boot and flowering. In addition, RM-16 was the site-year with the greatest yield losses in the absence of anthracnose control with fungicides. This suggests that early rainfall prior to the boot stage of the sorghum crop is a risk factor for anthracnose disease development and yield losses. Dissemination and germination of $C$. sublineola is water dependent (Leite and Nicholson 1992; Ngugi et al. 2000; Thakur and Mathur 2000) and expansion of the anthracnose lesion and formation of acervuli is favored by temperatures near $30^{\circ} \mathrm{C}$ (Crouch and Beirn 2009). Average monthly temperature of $25^{\circ} \mathrm{C}$ or greater and high precipitation events likely contributed to early disease onset and progression and yield losses at some locations in the current study. For experiments in Suffolk, Virginia, and Lewiston, North Carolina, in 2017 (SF-17 and LW-17, respectively), disease onset was early, but the progression was slow until flowering. As the crop entered reproductive stages, disease severity increased rapidly, which is similar to previous reports ( $\mathrm{Li}$ and TeBeest 2009; Ngugi et al. 2000) where slow anthracnose development was observed prior to flowering. Despite the slower disease development for the SF-17 and LW-17 experiments compared with RM-16, all three site-years had yield losses in the absence of disease control with fungicides. This suggests that early disease onset, which is associated with early-season rain events, may be more predictive of potential yield losses and need for fungicides than severity of anthracnose observed at flowering of the sorghum crop. Hence, regular scouting is suggested at early developmental stages when plants are close to boot stage, and decisions to apply a fungicide should be based on the presence of disease. Results from this study indicate that fungicide application at the flowering stage is critical for disease control and to protect yield. Application of fungicides may not be profitable if disease is absent prior to the flowering stage, as we did not see any significant yield differences between nontreated and treated plots under

Table 5. Correlation between foliar anthracnose severity and yield and minimum and maximum disease severity and yield at eight site-years in Virginia and North Carolina

\begin{tabular}{|c|c|c|c|c|c|c|c|c|}
\hline \multirow[b]{2}{*}{ Site $^{x}$} & \multicolumn{4}{|c|}{$\begin{array}{c}\text { Correlation, disease severity versus } \\
\text { yield }^{\mathbf{y}}\end{array}$} & \multicolumn{2}{|c|}{ Disease severity $(\%)^{\mathbf{Z}}$} & \multicolumn{2}{|c|}{ Yield (kg/ha) } \\
\hline & $r$ & $P$ value & Slope & Intercept & Minimum & Maximum & Minimum & Maximum \\
\hline SF-15 & 0.04 & 0.67 & 3 & 4,584 & 53 & 75 & 3,117 & 5,838 \\
\hline RM-15 & -0.01 & 0.93 & -1 & 3,755 & 43 & 75 & 1,814 & 8,317 \\
\hline RM-16 & -0.79 & $<0.01$ & -85 & 5,130 & 5 & 50 & 814 & 5,205 \\
\hline KS-16 & 0.27 & 0.01 & 16 & 5,046 & 1 & 55 & 4,008 & 7,754 \\
\hline SF-17 & -0.86 & $<0.01$ & -66 & 5,351 & 0 & 60 & 1,065 & 7,546 \\
\hline RM-17 & -0.17 & 0.09 & -12 & 6,016 & 0 & 45 & 3,456 & 7,748 \\
\hline LW-17 & -0.75 & $<0.01$ & -27 & 4,764 & 2 & 95 & 1,791 & 6,822 \\
\hline KS-17 & -0.22 & 0.03 & -27 & 4,058 & 0 & 40 & 1,501 & 6,655 \\
\hline
\end{tabular}

${ }^{\mathrm{x}}$ Experiment locations were as follows: $\mathrm{SF}=$ Suffolk, Virginia (Tidewater Agricultural Research and Extension Center); RM = Rocky Mount, North Carolina (Upper Coastal Plain Research Station); KS = Kinston, North Carolina (Casewell Development Center Research Farm); and LW = LewistonWoodville, North Carolina (Peanut Belt Research Station). Numbers 15, 16, and 17 following the location abbreviation indicate the years 2015, 2016, and 2017, respectively.

y $r=$ Pearson's correlation coefficient.

${ }^{\mathrm{z}}$ Anthracnose severity was rated as a visual estimate of the percent leaf area with signs and symptoms of sorghum anthracnose. 
low disease severity or when disease onset occurred after flowering. Our results are in accordance with two other studies (Fromme et al. 2017; Weisz et al. 2011) that showed that application of fungicides at low or no disease conditions does not increase grain yields in agronomic crops.

Yield protection with fungicide treatments was only observed for three experiments that had early disease onset followed by relatively high levels of foliar anthracnose in nontreated controls. Even though boot and flowering fungicide applications were applied 3 to 18 days after disease onset, they effectively protected reduced anthracnose severity and protected yield. This is likely because initial infections were observed on the lower leaves and did not reach the flag leaf until several weeks after disease onset; thus, fungicide applications between the boot and flowering stages protected the upper canopy that provides a majority of the photosynthates for the developing grain. For the SF-15 and RM-15 experiments, anthracnose severity was high, but yield did not differ among fungicides or application timings, which could be a result of heavy precipitation toward the end of the growing season that resulted in lodging, shattering of grains, and sprouting in heads (personal observation). For the KS-16 and

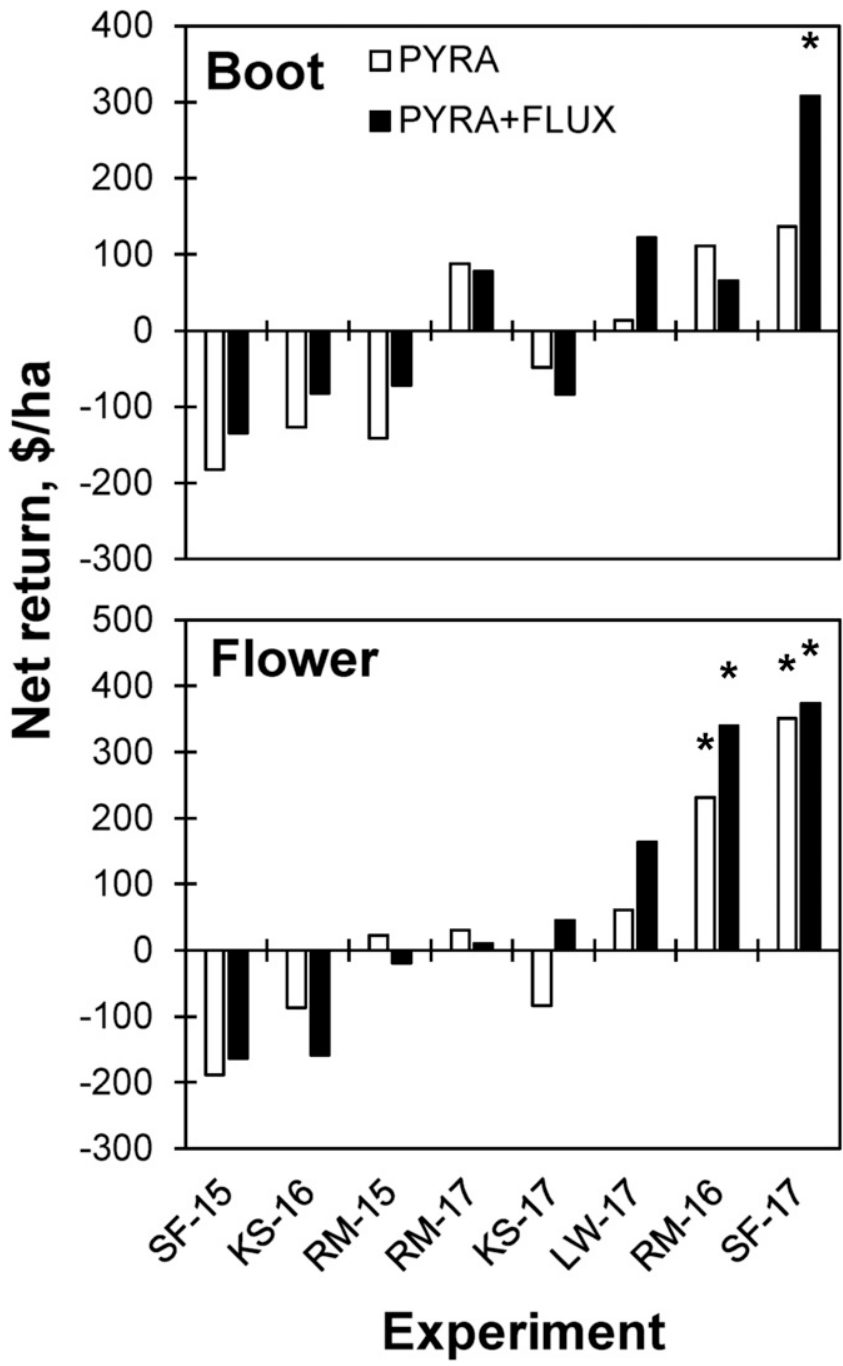

Fig. 3. Net return from a single application of pyraclostrobin (PYRA, as Headline; white bars) and pyraclostrobin plus fluxapyroxad (PYRA+FLUX, as Priaxor; black bars) applied to sorghum across eight experiments. SF = Suffolk, Virginia; RM = Rocky Mount, North Carolina; LW = Lewiston-Woodville, North Carolina; and KS = Kinston, North Carolina. Numbers 15, 16, and 17 following the location abbreviation indicate the years 2015, 2016, and 2017, respectively. Net return was calculated as the value (in U.S. dollars/ha) of the difference in yield between the fungicide-treated plots and the nontreated control minus the estimated cost of the fungicide application. Bars with an asterisk are from treatments that had significantly greater grain yield compared with the nontreated control within the experiment.
RM-17 experiments, there was no difference in yield among fungicide treatments, which could be attributable to lower disease severity at these site-years. The Pioneer $84 \mathrm{P} 80$ hybrid used in this study is highly susceptible to anthracnose but also has high yield potential (Balota and Oakes 2018). Hence, under low disease pressure, this hybrid generally produced high grain yield. This indicates that application of fungicides in the absence of disease or when disease pressure is low does not produce a yield benefit.

Leaf anthracnose severity as low as $20 \%$ is reported to impact sorghum grain yield (Ngugi et al. 2000). Our study also shows a significant negative correlation between leaf anthracnose severity and yield. Based on our results, for every percent increase in leaf anthracnose, there is a 27 to $85 \mathrm{~kg} / \mathrm{ha}$ loss in grain yield, which is a greater range compared with a recent study from Brazil that reported a 11 to $39 \mathrm{~kg} / \mathrm{ha}$ reduction in yield for each percent increase in anthracnose severity in susceptible sorghum genotypes (Cota et al. 2017). The greater range in yield reduction might be attributable to the greater number of experimental sites in this study. This illustrates the importance of managing sorghum anthracnose in the mid-Atlantic and other regions where environmental conditions favor fungal disease development.

Pyraclostrobin and pyraclostrobin plus fluxapyroxad were the only two fungicides that consistently reduced anthracnose severity, protected yield, and increased farm profitability with a single application at flowering. Hence, inclusion of a single application of a pyraclostrobin-based fungicide is likely to be beneficial when anthracnose onset is early and environmental conditions are favorable for disease development. Application of these fungicides after flowering did not protect yield, and applications following this stage of crop development are unlikely to be profitable to growers. The use of pyraclostrobin plus fluxapyroxad is more economical than pyraclostrobin even though the price of pyraclostrobin plus fluxapyroxad per liter (\$120.2/liter) is greater compared with that of pyraclostrobin (\$111.0/liter). This is because a smaller quantity of pyraclostrobin plus fluxapyroxad (0.29 liters/ha) is enough to reduce anthracnose severity, protect yield, and increase farm income compared with 0.44 liters of pyraclostrobin/ha.

Even though pyraclostrobin-containing fungicides provided the most consistent anthracnose control and yield protection, a single application or three applications of azoxystrobin reduced anthracnose severity in some experiments. This is in contrast to a study in Brazil that identified three applications of azoxystrobin as one of the most effective fungicides to control sorghum anthracnose (Pinto 2003). However, single applications of fungicides were not evaluated in this study. Regardless, based on this and the current study, azoxystrobin may be an alternative if pyraclostrobin and pyraclostrobin plus fluxapyroxad are not available, whereas propiconazole and picoxystrobin did not reduce anthracnose severity under field conditions, even after three applications. The limited number of effective fungicide active ingredients and modes of action labeled for control of sorghum anthracnose indicates a high risk for fungicide resistance development within populations of $C$. sublineola. The fungicide active ingredient pyraclostrobin is in the quinone outside inhibitor class, which is categorized as a high risk for fungicide resistance development especially if it is not rotated with different fungicide modes of action (da Costa et al. 2011; Moore et al. 2010; Rosewich et al. 1998). Fungicides, premixes, or tank mixes with different modes of action to rotate with pyraclostrobin should be explored to reduce the potential development of fungicide resistance. The fungicide Priaxor is a mixture of pyraclostrobin and fluxapyroxad. Fluxapyroxad is a member of the succinate dehydrogenase inhibitor class of fungicides. This premix fungicide may have a relatively reduced risk of resistance development compared with pyraclostrobin alone, but it will still be important in the future for additional fungicide modes of action to be labeled for anthracnose control in sorghum.

The climate of the mid-Atlantic is warm and humid compared with the major sorghum growing regions in the United States and provides suitable conditions for anthracnose epidemics that may severely impact yield and farm profitability. Anthracnose development and dispersal is temperature and precipitation dependent. 
Based on the current study conducted in the mid-Atlantic United States, when average temperatures $\geq 25^{\circ} \mathrm{C}$ are accompanied by frequent or heavy rainfall events, anthracnose onset occurs earlier and more rapid rates of disease development are observed. If anthracnose symptoms and signs are observed at or before the boot stage, there is a greater chance of disease outbreaks and yield losses later in the season. Thus, the sorghum crop should be scouted for disease when the crop is approaching the boot stage. A single application of fungicide (pyraclostrobin or pyraclostrobin plus fluxapyroxad) is warranted if anthracnose onset is at or prior to the boot stage and should be applied no later than flowering to reduce anthracnose severity, protect yield, and increase farm profitability, particularly when a susceptible hybrid is being grown. In the absence of anthracnose prior to flowering, fungicide application is unlikely to protect yield or farm profitability. In this study, we did not consider the effect of host resistance on management of sorghum anthracnose. Therefore, future studies will focus on the integrated effect of host resistance and fungicide applications on anthracnose management and yield in sorghum production in the mid-Atlantic region of the United States.

\section{Acknowledgments}

We thank current and former members of the Mehl and Everman laboratories for help with establishing, maintaining, and harvesting experimental plots.

\section{Literature Cited}

Balota, M., and Oakes, J. 2018. Virginia Grain Sorghum Performance Tests 2017. Publication VT/0218/CSES-227NP. Virginia Polytechnic Institute and State University and Virginia Cooperative Extension, Blacksburg, Virginia.

Balota, M., Thomason, W. E., Mehl, H. L., Cahoon, C. W., Reay-Jones, F., Taylor, S. V., Flessner, M. L., and Everman, W. 2018. Revival of grain sorghum in the mid-Atlantic. Crops Soils 51:32-47.

Cardwell, K. F., Hepperly, P. R., and Frederiksen, R. A. 1989. Pathotypes of Colletotrichum graminicola and seed transmission of sorghum anthracnose. Plant Dis. 73:255-257.

Cota, L. V., Souza, A. G. C., Costa, R. V., Silva, D. D., Lanza, F. E., Aguiar, F. M., and Figueiredo, J. E. F. 2017. Quantification of yield losses caused by leaf anthracnose on sorghum in Brazil. J. Phytopathol. 165:479-485.

Crouch, J. A., and Beirn, L. A. 2009. Anthracnose of cereals and grasses. Fungal Divers. 39:19-44.

Cuevas, H. E., Prom, L. K., Erpelding, J. E., and Brotons, V. 2014. Assessments of genetic diversity and anthracnose disease response among Zimbabwe sorghum germplasm. Plant Breed. 133:234-242.

da Costa, R. V. D., Zambolim, L., Cota, L. V., Silva, D. D. D., Rodrigues, J. A. S., Tardin, F. D., and Casela, C. R. 2011. Genetic control of sorghum resistance to leaf anthracnose. Plant Pathol. 60:1162-1168.

de Mendiburu, F. 2015. Agricolae: Statistical procedures for agricultural research. $\mathrm{R}$ package version 1.2-2. https://CRAN.R-project.org/package=agricolae

Flessner, M., and Taylor, S. V. 2019. Pest Management Guide: Field Crops, 2019. Publication 456-016 (ENTO-288P). Virginia Polytechnic Institute and State University and Virginia Cooperative Extension, Blacksburg, VA. https:// www.pubs.ext.vt.edu/456/456-016/456-016.html
Fromme, D. D., Price, T., Lofton, J., Isakeit, T., Schnell, R., Dodla, S., Stephenson, D., Grichar, W. J., and Shannon, K. 2017. Effect of fungicide applications on grain sorghum (Sorghum bicolor L.) growth and yield. Int. J. Agron. 2017: 5927816

Gwary, D. M., Bwatanglang, N., and Bdliya, B. S. 2008. Integrated management of sorghum anthracnose through the use of fungicides, crop varieties and manipulation of sowing dates in Sudan Savanna of Nigeria. Int. J. Agric. Biol. 10:661-664.

Gwary, D. M., Mailafiya, D. M., and Jibrin, T. J. 2006. Survival of Colletotrichum sublineolum and other seed-borne fungi in sorghum seeds after twenty months of storage. Int. J. Agric. Biol. 8:676-679.

Leite, B., and Nicholson, R. L. 1992. Mycosporine-alanine: A self-inhibitor of germination from the conidial mucilage of Colletotrichum graminicola. Exp. Mycol. 16:76-86

Li, Y., and TeBeest, D. O. 2009. Temporal and spatial development of sorghum anthracnose in Arkansas. Plant Dis. 93:287-292.

Lopez, J. A., Rojas, K., and Swart, J. 2015. The economics of foliar fungicide applications in winter wheat in Northeast Texas. Crop Prot. 67:35-42.

Marley, P. S. 2004. Effects of integrating host plant resistance with time of planting or fungicides on anthracnose and grain mould and yield of sorghum (Sorghum bicolor) in the Nigerian northern Guinea Savanna. J. Agric. Sci. 142:345-350.

Marley, P. S., Diourte, M., Neya, A., and Rattunde, F. W. 2005. Sorghum anthracnose and sustainable management strategies in West and Central Africa. J. Sustain. Agric. 25:43-56.

Moore, J. W., Ditmore, M., and TeBeest, D. O. 2010. Development of anthracnose on grain sorghum hybrids inoculated with recently described pathotypes of Colletotrichum sublineolum found in Arkansas. Plant Dis. 94:589-595.

Ngugi, H. K., Julian, A. M., King, S. B., and Peacocke, B. J. 2000. Epidemiology of sorghum anthracnose (Colletotrichum sublineolum) and leaf blight (Exserohilum turcicum) in Kenya. Plant Pathol. 49:129-140.

Pande, S., Thakur, R. P., Karunakar, R. I., Bandyopadhyay, R., and Reddy, B. V. S. 1994. Development of screening methods and identification of stable resistance to anthracnose in sorghum. Field Crops Res. 38:157-166.

Pinto, N. F. J. A. 2003. Chemical control of the anthracnose (Colletotrichum graminicola) of sorghum. Rev. Bras. Milho Sorgo Brazil 2:148-152.

Rosewich, U. L., Pettway, R. E., McDonald, B. A., Duncan, R. R., and Frederiksen, R. A. 1998. Genetic structure and temporal dynamics of a Colletotrichum graminicola population in a sorghum disease nursery. Phytopathology 88:1087-1093.

Tesso, T., Perumal, R., Radwan, G. L., Little, C. R., Pro, L. K., Adeyanju, A., and Magill, C. W. 2012. Sorghum pathology and biotechnology - a fungal disease perspective: Part II. Anthracnose, stalk rot, and downy mildew. Eur. J. Plant Sci. Biotechnol. 6:31-44.

Thakur, R. P., and Mathur, K. 2000. Anthracnose. Pages 10-12 in: Compendium of Sorghum Diseases. Frederiksen, R. A., and Odvody, G. N., eds. American Phytopathological Society, St. Paul, MN.

U.S. Department of Agriculture Foreign Agricultural Service. 2019. World Agricultural Production. Circular Series WAP 5-19:1-31. https://apps.fas.usda.gov/ psdonline/circulars/production.pdf

U.S. Department of Agriculture National Agricultural Statistical Service. 2018 Crop Production. https://www.nass.usda.gov/Publications/Todays_Reports/reports/ crop0918.pdf

Vanderlip, R. L., and Reeves, H. E. 1972. Growth stages of sorghum [Sorghum bicolor (L.) Moench]. Agron. J. 64:13-16.

Weisz, R., Cowger, C., Ambrose, G., and Gardner, A. 2011. Multiple mid-Atlantic field experiments show no economic benefit to fungicide application when fungal disease is absent in winter wheat. Phytopathology 101:323-333. 